\title{
'n BENADERING TOT VERGOEDING IN 'N SUID-AFRIKAANSE NYWERHEIDSGROEP MET SPESIFIEKE VERWYSING NA NIE- BLANKE LONE EN SALARISSE
}

\author{
D. TROMP \\ STELLENBOSCH - BOEREWYNMAKERY
}

\begin{abstract}
SUMMARY
The compensation scene in South Africa is changing rapidly. One of the main reasons for this change is the fact that large companies are now becoming more aware of their responsibility towards all their stakeholders, of which their labour force happens to be a very important one. The company referred to in this article, realised its responsibility towards its labour force and adopted a philosophy of equal remuneration opportunities for all its workers. This brought about a programme for eliminating the so called "wage gap". The philosophy, strategy and policy regarding compensation in the company and the current situation in South Africa regarding non-white compensation are discussed. Special attention is paid to the method according to which the compensation structure in the company is presently being redesigned.
\end{abstract}

Vir die bedryfsleier is " $n$ wetenskaplike maar ook praktiese vergoedingsbeleid en stelsel ' $n$ voorvereiste vir die daarstelling, instandhouding en motivering van sy arbeidsmag op so "n wyse dat hy so suksesvol moontlik kan fungeer.

Die vergoedingstelsel wat in hierdie artikel bespreek word, verteenwoordig 'n poging om ' $n$ stelsel te ontwikkel wat nie alleen gegrond is op wetenskaplike beginsels en metodes nie, maar wat ook voldoen aan die praktiese vereistes wat daaraan gestel word. Dit word egter nie voorgehou as ' $n$ ideale stelsel nie - elke organisasie het immers sy besondere kenmerke waarby ' $n$ vergoedingstelsel moet aanpas. Verder is daar gou besef dat geen vergoedingstelsel ooit gesien kan word as "n stelsel wat slegs ontwerp en in stand gehou kan word nie. Die voortdurende hersiening en ontwikkeling van die bestaande stelsel is dus 'n belangrike aspek van die vergoedingsbeleid.

In hierdie proses van ontwikkeling van 'n geskikte vergoedingstruktuur het verskeie aspekte reeds opgeduik wat vir die voornemende of praktiserende personeelspesialis interessant mag wees. 
Ten einde oor ' $\mathrm{n}$ spesifieke vergoedingsplan te besluit is die oogmerke van die vergoedingsfunksie eers gedefinieer, daarna is op 'n bepaalde vergoedingstrategie besluit, ' $n$ beleid is bepaal en hierbinne is spesifieke metodes en tegnieke gevolg.

Die oogmerke van die maatskappy met betrekking tot die vergoedingsfunksie kan soos volg gedefinieer word:

"Om mannekrag te bekom, te behou en te motiveer deur middel van die regte vergoeding."

Hieruit volg ' $n$ bepaalde vergoedingstrategie wat die tegniek en taktiek van die vergoedingsfunksie bepaal.

Die mees fundamentele aspek daarvan is dat die beginsel van gelyke betaling vir gelyke werk vir alle werknemers in die praktyk toegepas word deur ' $n$ uniforme salarisskaal in te stel. So ' $n$ uniformiteit verseker nie alleen in die algemeen 'n verhoogde lewenspeil vir SuidAfrika se middelklas nie, maar dra ook sorg dat almal daarin sal deel ongeag ras of kleur.

Hierdie benadering is dan ook in lyn met wat vandag in ander dele van die wêreld m.b.t. die arbeidsmark in swang is. In die V.S.A. het die begrip "belangegroepe" reeds sterk posgevat en word daar voortdurend verwys na die sogenaamde "sosiale verantwoordelikheid" van ondernemings. 'n Groot onderneming het verskeie belangegroepe waarvan die aandeelhouers (kapitaalverskaffers) slegs een is. Ander belangegroepe is die verbruikers van die produk wat die ondernemer vervaardig en/of verkoop, die voorsieners van grondstowwe, die werknemers van die onderneming en die omgewing waarbinne die onderneming opereer. Die een belangegroep mag nie te na gekom word ten koste van 'n ander nie. So "n filosofie van winsmaksimalisering ten koste van realistiese lone en salarisse, billike pryse, dienste aan die gemeenskap, ens., kan nie net "moreel” verkeerd wees nie, maar kan ook vir die onderneming se suksesvolle voortbestaan oor die langtermyn nadelig wees.

Wetgewing soos die "Fair Labour Standards Act", "Equal Pay Act", "Civil Rights Act", “Age Discrimination and Employment Act", ens. is in die V.S.A. van krag. Hierdie wette bepaal onderskeidelik minimum lone en verbied vergoedingsdiskriminasie op grond van geslag, ras en ouderdom. Veral insiggewend is die feit dat in huidige loonvasstellings nie gediskrimineer word tussen onderskeie rassegroepe nie en dat die minimum lone ten tye van 
die publikasie van die vasstelling in lyn was met die lone wat, volgens opnames, in die arbeidsmark betaal is. Hierdie vasstellings maak in die meeste gevalle ook voorsiening vir ' $\mathrm{n}$ verhoging in die minimum loon met verloop van tyd.

Teen die agtergrond van die reeds genoemde oogmerke en vergoedingstrategie, is die volgende onder andere as personeelbeleid aanvaar:

- Dat alle poste in die onderneming in spesifieke grade gegroepeer sal word aan die hand van wetenskaplike posbeskrywings en evaluerings.

- Dat daar vir elke posgraad 'n spesifieke salarisskaal moet wees wat baseer word op erkende salaris- en loonopnames in die arbeidsmark. Hierdie salarisskale moet so bereken word dat ' $\mathrm{n}$ wetenskaplike-korrekte struktuur daargestel word wat, wanneer nodig, aangepas kan word.

- Dat n werknemer se relatiewe posisie op die skaal wat op sy pos van toepassing is, sal afhang van sy werkverrigting soos bepaal volgens 'n optimaal geldige, betroubare en prakties bruikbare beoordelingstelsel. Ondervinding, kwalifikasie en ander biografiese kenmerke, (bv. ras) van werkers het dus 'n invloed op sy inkomste slegs in soverre dit sy werkverrigting beïnvloed.

\section{DIE VERGOEDING VAN NIE-BLANKES IN SUID-AFRIKA}

Uit die bostaande verduideliking van die betrokke onderneming se vergoedingsfilosofie, blyk dit dus dat daar geen onderskeid met betrekking tot blankes en nie-blankes gemaak word wat potensiële vergoeding betref nie. Daar is dus nie sprake van die sogenaamde "loongaping" wat die salarisstruktuur betref nie. Hierdie verwydering van die loongaping is sekerlik nie uniek nie. Die hele kwessie van nie-blanke vergoeding en die "loongaping" is trouens seker een van die mees aktuele onderwerpe waarmee sakeleiers en personeelbeamptes hulself vandag besig hou.

Daar is waarskynlik verskeie redes waarom daar vandag wel " $n$ "loongaping" bestaan tussen die vergoeding van blankes en nie-blankes wat werk verrig wat op dieselfde vlak of binne dieselfde posgraad val. Dit is wel so dat werk van 'n ongeskoolde aard in Suid-Afrika feitlik uitsluitlik deur nie-blankes verrig word en dat dit dus moeilik is om blanke en nieblanke vergoeding op hierdie vlak met mekaar te vergelyk en die omvang van die gaping te 
bepaal. Een of albei van die volgende twee benaderings kan moontlik meer lig op die saak werp:

- Verskeie instansies poog om aan te dui wat die verskil is tussen die werklike maandelikse verdienste van 'n ongeskoolde nie-blanke man en die maandelikse bedrag nodig vir hom en sy gesin om te bestaan. Na laasgenoemde syfer word gewoonlik as die "Poverty Datum Line" (P.D.L.) verwys. Ongelukkig kom hierdie instansies gewoonlik met verskillende syfers voor die dag en neem hulle ook nie die feit in ag dat meer as een lid van die gesin ekonomies bedrywig is en dus ' $n$ bydrae moet maak tot die gesin se totale inkomste nie.

Met 'n salarisopname as basis wat gebruik maak van 'n posevaluering- en graderingstelsel (soos byvoorbeeld die van PEROMNES) kan die gemiddelde maandelikse verdienste van die verskillende rassegroepe grafies teenoor die ooreenstemmende posgrade aangestip word. Wanneer die bespassende lyn deur hierdie punte getrek word, kan die gradiënt van die salarisstruktuur vir elke rassegroep bepaal word.

Hierdie lyne vorm gewoonlik eksponensiale kurwes, waarvan die gradiënt volgens die metode van kleinste kwadrate algebraïes bepaal kan word. Op hierdie wyse kan die kurwes dus verleng word (vergelyk Figuur 1) sodat daar ooreenstemmende waardes vir die verskillende rassegroepe oor al die verskillende posgrade bepaal kan word. (Die stippellyn-gedeelte van die kurwes dui die verlenging aan.)

'n Alternatiewe metode is om die gemiddelde salarisse per graad op semi-logaritmiese grafiekpapier aan te stip en dan die bespassendste reguitlyn deur die onderskeie punte te trek. Hierdie reguitlyn kan dan net verlang word ten einde ooreenstemmende waardes vir al die posgrade te bepaal. 


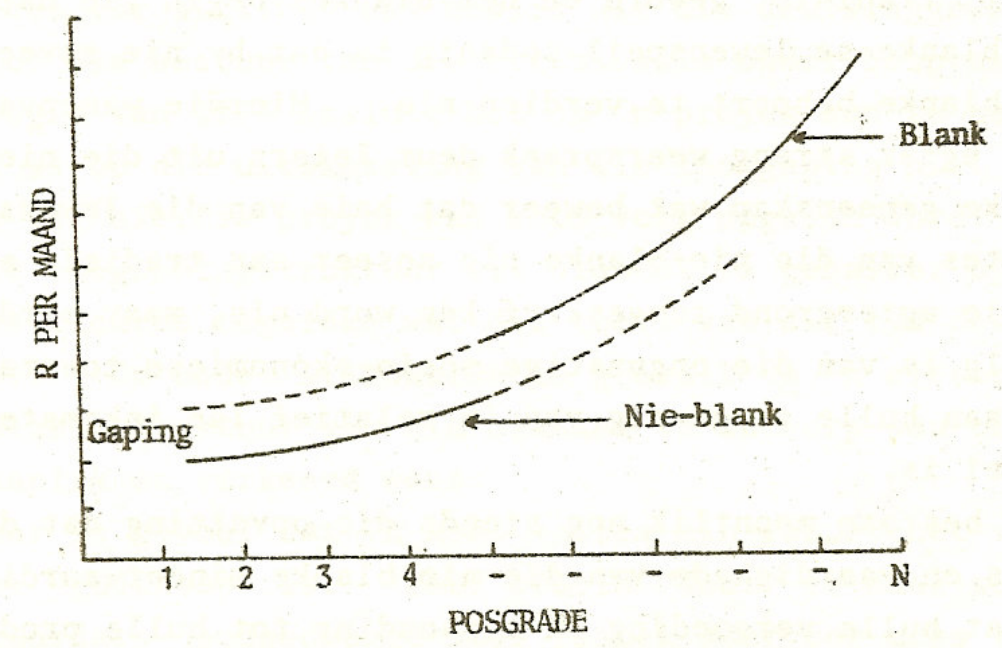

Figuur 1. Hipotetiese projeksies van vergoedingskurwes vir vir blanke en nie-blanke inkonste groepe.

Die redes vir hierdie "loongaping" in Suid-Afrika kan waarskynlik aan verskeie faktore toegeskryf word. Sommige hiervan die volgende:

- Die vraag- en aanbodsituasie van nie-blanke arbeid stel ondernemings in staat om relatief laag daarvoor te betaal. Hierdie situasie is egter besig om te verander as gevolg van die feit dat die myne voortaan tot ' $n$ groter mate arbeid sal moet werf binne die grense van die Republiek. Nie-blanke werknemers het tot onlangs geen bedingingskanale tot hulle beskikking gehad nie. Inmenging van die tuislandowerhede, werks- en skakelkomitees, en moontlik op 'n latere stadium, wetlik erkende nie-blanke of veelrassige vakbonde, verander ook hierdie aspek.

- Waarskynlik het lae lone vir nie-blankes deur die jare 'n soort "tradisie" geword en het blankes begin glo dat die nie-blanke se lewenspeil sodanig is dat hy nie soveel as die blanke behoort te verdien nie. Hierdie wanopvatting word egter streng weerspreek deur leiers uit die nie-blanke gemeenskap wat beweer dat baie van die lewensgewoontes van die nie-blanke nie soseer aan tradisie en kulturele agtergrond toegeskryf kan word nie, maar eerder die gevolg is van die ongunstige sosio-ekonomiese toestande waaraan hulle as gevolg van 'n relatief lae inkomste blootgestel is.

- Daar bestaan moontlik nog steeds die opvatting dat die vermoëns en vaardighede van die nie-blanke minderwaardig is en dat hulle vergoeding in verhouding tot hulle produktiwiteit wel realisties is. Die tekort aan geskikte blankes om alle poste op 'n hoër vlak van geskooldheid te vul en die suksesvolle opleiding en aanstelling 
van nie-blankes om hierdie tekort aan te vul, is vinnig besig om hierdie opvatting die nek in te slaan.

Afgesien van die geldigheid al dan nie van die redes vir die tradisionele loongaping, het bedryfsleiers die afgelope aantal jare onder die indruk gekom van die bedingingsmag van nieblanke arbeid - nieteenstaande die feit dat huidige wetgewing nie volkome daarvoor voorsiening maak nie.

Die wetregtelike situasie ter syde, sal dit nietemin die bestuur van ondernemings oor die langtermyn tot voordeel strek indien hul verseker dat hulle vergoedingstrukture so in orde gebring word dat arbeidsonrus as gevo1g van loongapings gehee1 en a1 voorkom word.

\section{NIE-BLANKE VERGOEDING TER PLAATSE}

Vrees vir stakings was beslis nie die deurslaggewende faktor toe die bestuur van die organisasie onder bespreking aan die begin van 1973 besluit het om 'n projek aan te pak wat gemik is op die uitskakeling van die loongaping nie. Die redes vir hierdie projek kan soos volg opgesom word:

- Die vergoedingstruktuur vir blankes is gebaseer op gesofistikeerde tegnieke wat die toets van die tyd deurstaan het. Om ander standaarde te gebruik om 'n eiesoortige salarisstruktuur vir nie-blankes te ontwerp sou onwetenskaplik en verkeerd wees.

- Daar is gevoel dat "n mens basies min respek het vir iets wat "goedkoop" is. Deur arbeid "duur" te maak sou bestuurders noodgedwonge meer respek daarvoor moes toon en meer aandag aan meer wetenskaplike keuring, plasing, opleiding en benutting van sy arbeidsmag moes gee.

- Meer as 'n derde van die betrokke onderneming se inkomste is afkomstig van nieblankes. Daarbenewens vorm nie-blankes nagenoeg $80 \%$ van sy totale arbeidsmag. Soos vroeër aangedui, word geglo dat verbruikers en werknemers vername belangegroepe is en dat die organisasie nie anders kan as om sy sosiale verantwoordelikheid in hierdie opsig na te kom nie.

- $\quad$ Dit is moeilik te bedink hoe om mense te motiveer as hulle basiese behoeftes nie bevredig is nie. Alhoewel hoë lone op sigself nie noodwendig sal meebring dat nie-blankes meer produktief is nie, verseker dit ten minste dat die aanbod van 
arbeid sodanig is dat beter werkers gelok kan word en dat hulle by die onderneming aanbly. Dit gee aan bestuur die geleentheid om nie-blankes met potensiaal op te lei en te ontwikkel.

- $\quad$ Ten spyte van bewerings dat verhoging in die vergoeding van nie-blankes daartoe kan lei dat ondernemings hul arbeidsmag verminder en sodoende aanleiding gee tot werkloosheid, is daar gevoel dat 'n hoër lewenstandaard vir almal aanleiding sal gee tot hoër kwalifikasies, beter opleiding, 'n hoër vraag na goedere en dienste en dus meer werksgeleenthede, veral op 'n meer geskoolde vlak.

- $\quad$ Ten einde vir sy aandeelhouers voortgesette groei te verseker, moet die onderneming in staat wees om binne 'n stabiele omgewing te funksioneer. Vir die bestuur van die betrokke onderneming is nie-diskriminerende vergoedingspraktyke 'n belangrike onderdeel van sosiale en dus ook bedryfstabiliteit.

'n Ontleding van die vergoedingstruktuur wat vir die betrokke onderneming aan die begin van 1973 gedoen is, het getoon dat die situasie soos aangetoon in Figuur 1, ook binne die onderneming bestaan. Daar was dus verskillende loonskale in werking vir blankes en nieblankes in ooreenstemmende posgrade. In die lig van die filosofie van die bestuur van die onderneming, soos hierbo verduidelik, is daar besluit om hierdie "loongaping" so spoedig moontlik uit te skakel.

Die betrokke onderneming is redelik arbeidsintensief en as gevolg van die relatief hoë kostes verbonde aan die uitskakeling van die loongaping, is aanvanklik besluit om die gaping in 3 stappe uit te wis, naamlik op 1 April 1973, 1 April 1974 en 1 April 1975. Afgesien van die koste-oorweging, sou dit ook onverantwoordelik wees om die gaping in een stap toe te maak omdat dit nie genoeg tyd sou laat om die nodige maatreëls te tref om ook die produktiwiteit van die werkers te verhoog nie. Die aspekte wat vooraf in ag geneem moes word, was die volgende:

- Wat sou die reaksie van die blanke werkers wees?

- Watter bedrag sou die bestuur van die onderneming bereid wees om vir hierdie projek te bewillig? 
- $\quad$ Op welke wyse sou produktiwiteit verhoog kon word? Die antwoord het tot ' $\mathrm{n}$ groot mate by die opleiding van eerstelyn toesighouers skyn te lê. Programme moes dus vir hierdie doel ontwikkel word.

- $\quad$ 'n Ander probleem was dat vinnige verhogings vir nie-blankes hulle vlak van verwagting sou beïnvloed. Sodra die projek afgehandel is, sou die grootte van die verhogings weer na "normaal" moet terugkeer. Om op dieselfde loonskaal as blankes te wees sou ook meebring dat hulle waarskynlik sou verwag dat alle ander diensvoorwaardes ook dieselfde moes wees, sommige waarvan ongelukkig buite die beheer van die betrokke onderneming se bestuur val.

Daar is besluit om op 1 April 1973 verhogings van $20 \%$ tot $25 \%$ aan nie-blankes toe te staan teen 'n koste van sowat R800 000 per jaar. Vir hierdie doel is 'n aparte stel skale as tussen-maatreë ontwikkel (vergelyk Figuur 2). (Die kurwes stel die minimum salaris in elke graad voor.) Die blanke struktuur is voorlopig onveranderd gelaat aangesien daar binne die individuele grade en skale voldoende ruimte vir individuele salarisverhogings was.

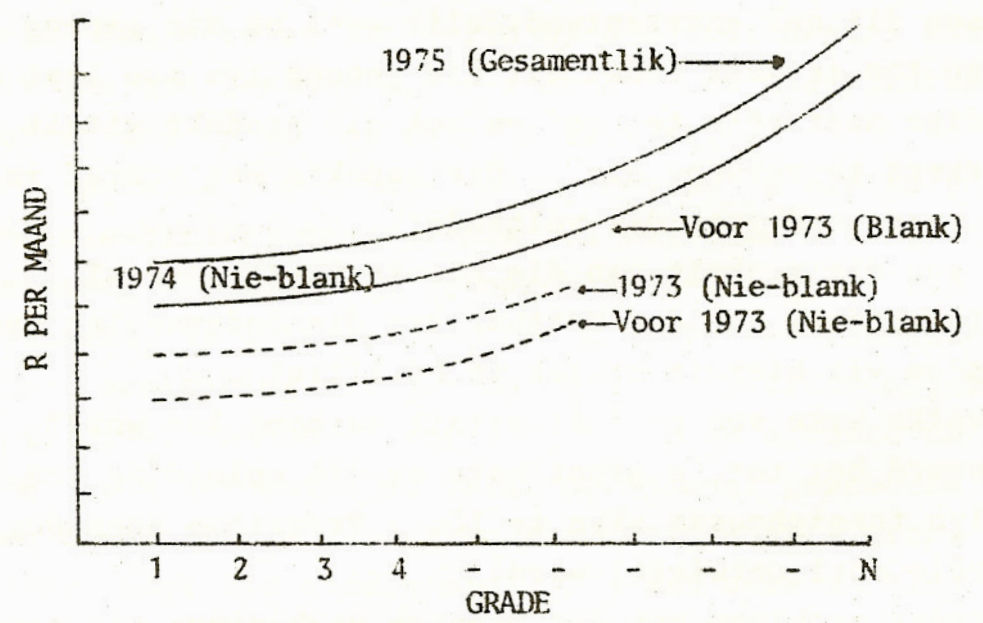

Figur 2. Vergoedingskurwes vir blanke en nie-blanke werknemers op verskillende stadia van uitwissing van die loongaping. 
Op 1 April 1974 is die nie-blanke struktuur in lyn gebring met die bestaande blanke struktuur deur die waardes van laasgenoemde eksponensiale kurwe algebraïes te bepaal en volgens die formule van die k1einste kwadrate hierdie waardes toe te pas op die nie-blanke kurwe. Sou hierdie kurwe dus op semi-logaritme papier getrek word, sal dit 'n reguitlyn vorm. Hierdie stap het sowat R750 000 per jaar gekos en weer eens verhogings van sowat $20-25 \%$ vir die nie-blankes teweeggebring. Die blankes is weer op dieselfde wyse as gedurende die vorige jaar hanteer. Vanaf hierdie datum word werknemers dus vergoed vo1gens die skaal wat op hulle van toepassing is, afgesien van kleur of ras.

Daar word beoog om op 1 April 1975 die totale struktuur te hersien. Beide blank en nie-blanke salarisse sal dus binne hierdie uniforme struktuur aangepas word.

Om hierdie enkellyn struktuur wat vanaf 1 April 1975 van toepassing sal wees, te ontwerp aan die hand van markopnamesyfers, het sekere probleme meegebring. Die mees algemene metode is om die middelpunte van die skale vir die onderskeie grade te bepaal in ooreenstemming met die markgemiddelde vir die betrokke graad. Die skaal-minima en maksima word dan om hierdie gemiddeld bereken sodat die skale 'n 40 - $50 \%$ omvang het.

'n Ander benadering is om as minimum en maksimum een standaardafwyking bo en onder die markgemiddelde te neem. Ongelukkig is daar wat markgemiddeldes betref in SuidAfrika nog besliste verskille tussen rasse en geslagsgroepe en kon die nuwe struktuur nie soos hierbo verduidelik, ontwerp word nie.

Daar is gevolglik op grond van die markgegewens t.o.v. nie- blankes bes1uit wat die minimumloon vir 'n ongeskoolde werker behoort te wees. Daarna is daar besluit dat die onderneming in sekere van die "middelgrade" waarin gegradueerde personeel direk na afloop van hul opleiding aangestel word, mededingend moet wees. Hier is die markgegewens ten opsigte van blanke mans, as basis geneem. Derdens is daar besluit dat die organisasie in die hoër grade meer as net mededingend wil wees sodat hoë kwaliteit senior personeel bekom en beloon kan word en is " $n$ waarde ietwat hoër as die markgemiddelde vir blanke mans gekies as skaalmiddelpunt. Met hierdie waardes as basis is die struktuur deur middel van die metode van kleinste kwadrate, algebraïes bereken. Die verskille tussen markgemiddeldes ten opsigte van die verskillende rasse- en geslagsgroepe word egter binne die omvang van die skale geakkommodeer.

Wat belangrik is, is die feit dat die enkellyn-struktuur ' $n$ konstante gradiënt het. In sommige ondernemings word daar wel verwys na enkellyn salarisstrukture waar die gradiënt 
verander oor die laer grade vanaf die markgemiddelde vir blankes na die markgemiddelde vir nie-blankes. In sulke gevalle kan die betrokke instansies nie noodwendig tevrede voel dat hulle deurgaans gelyke vergoedingsgeleenthede aan alle lede van die arbeidsmag bied nie.

Aandag is ook aan die metode van betaling geskenk. Voor 1 April 1973 is die meeste nie-blankes weekliks betaal. Slegs enkeles in hoër grade was maandeliks betaal. Daar is gevoel dat daar besliste voordele daaraan verbonde is om alle personeel maandeliks te betaal. Die belangrikste hiervan is die volgende:

- $\quad$ Die lonekantoor moes elke Vrydag 'n aansienlike bedrag aan kontant hanteer en uitbetaal. Deur werknemers maandeliks deur middel van 'n deposito in sy bankrekening te betaal word 'n administratiewe las sowel as die risiko verbonde aan die hantering van kontant, aansienlik verlig.

- Die nie-blanke self ontvang nie kontant wat hy moontlik mag verloor of van hom gesteel kan word nie. Die feit dat sy salaris by 'n bank of bouvereniging inbetaal word, dwing hom om 'n spaarrekening te open en sal hom hopelik tot groter spaarbewustheid aanspoor.

- $\quad$ Nie-blankes moet ook die meeste van hulle finansiële verpligtinge soos die betaling van huishuur, huurkooppaaiemente, ensovoorts, maandeliks nakom. Indien hulle dus ook maandeliks betaling ontvang, behoort dit vir hulle baie makliker te wees om hulle finansiële sake te reël.

- Om maandeliks betaal te word, net soos die blanke en ander senior nie-blankes, het 'n sekere mate van statuswaarde.

Aanvanklike meningsopnames deur die personeeldepartement het getoon dat die nieblankes self nie ten gunste van maandelikse betaling is nie. Daar is egter deur die personeeldepartement gevoel dat hulle nie die voordele behoorlik besef nie en daar is besluit om tog voort te gaan met die planne om hulle na 'n maandelikse betaalstelsel oor te skakel, maar om dit wel nie in een stap nie, maar geleidelik te doen. Aanvanklik is alle nie-blankes wat in die meningsopname ten gunste van maandelikse betaling was, sowel as enige ander nie-blankes wat dit verkies, na die maandelikse stelsel oorgeskakel. Alle persone wat nuut aangestel is, is ook onmiddellik by diensaanvaarding op die maandelikse stelsel geplaas. Vandag word meer as die helfte (ongeveer $60 \%$ ) van die nie-blanke personeel by die betrokke onderneming se hoofkantoor en grootste operasionele eenheid reeds maandeliks betaal. Die res begin vinnig 
die voordele hieraan verbonde insien en daagliks word versoeke ontvang van werknemers wat na maandelikse besoldiging oorgeplaas wil word.

\section{SLOTOPMERKING}

Nie-Blanke vergoeding in Suid-Afrika is vinnig besig om te verander - nie slegs ten opsigte van loonvlakke nie, maar ook sover dit die struktuur, samestelling daarvan, byvoordele en ander diensvoorwaardes aangaan.

Die loongapingsprojek soos in die voorafgaande paragrawe beskryf, het spoedig reeds die voordele van die stap aan die lig gebring en daar word tans gepoog om die benadering nog verder te probeer deurvoer en die filosofie van die bestuur van die onderneming van gelyke geleenthede, op ander gebiede ook tot praktiese uitvoering te bring.

\section{OPSOMMING}

Die vergoedings-prentjie in Suid-Afrika is vinnig besig om te verander. Een van die belangrikste redes hiervoor is dat groot ondernemings gaandeweg meer en meer bewus word van hulle verantwoordelikhede teenoor al hulle belangegroepe, waarvan die arbeidsmag ' $n$ baie belangrike een is. Die betrokke onderneming waarna in die bostaande artikel verwys word, het as gevolg van sy besef van hierdie verantwoordelikheid teenoor sy werknemers, ' $n$ filosofie van gelyke geleenthede om dieselfde te kan verdien vir dieselfde werk, aanvaar. Dit het 'n program meegebring waarvolgens die sogenaamde "loongaping" uitgeskakel moes word. In die voorafgaande artikel word stilgestaan by die filosofie, strategie en beleid ten opsigte van vergoeding in die betrokke onderneming, die situasie met betrekking tot die "loongaping" en die vergoeding van nie-blankes in Suid-Afrika en die wyse waarop die vergoedingstruktuur van die betrokke onderneming herontwerp word om die "loongaping" uit te skakel. 